\title{
Globe
}

Revue internationale d'études québécoises

\section{Yvan Lamonde : Histoire sociale des idées au Québec. Volume 1, 1760-1896, Montréal, Fides, 2000}

\section{Michel Lacroix}

Volume 4, numéro 1, 2001

URI : https://id.erudit.org/iderudit/1000607ar

DOI : https://doi.org/10.7202/1000607ar

Aller au sommaire du numéro

Éditeur(s)

Globe, Revue internationale d'études québécoises

ISSN

1481-5869 (imprimé)

1923-8231 (numérique)

Découvrir la revue

Citer ce compte rendu

Lacroix, M. (2001). Compte rendu de [Yvan Lamonde : Histoire sociale des idées au Québec. Volume 1, 1760-1896, Montréal, Fides, 2000]. Globe, 4(1), 146-149.

https://doi.org/10.7202/1000607ar d'utilisation que vous pouvez consulter en ligne.

https://apropos.erudit.org/fr/usagers/politique-dutilisation/ 
individus qui n'en ont pas reçu. Et ainsi de suite. Le récit que fait l'auteur a une certaine valeur, mais l'analyse, hélas, manque de rigueur.

Michael R. Smith

Université McGill

\section{Yvan Lamonde}

Histoire sociale des idées au Québec.

Volume 1, 1760-1896, Montréal, Fides, 2000.

Après trente ans de recherches sur l'histoire culturelle québécoise, Yvan Lamonde nous livre la première tranche de son opus magnum, sa magistrale Histoire sociale des idées au Québec, qui dépassera sans doute, avec la parution du second volume, le seuil des mille pages. Tant par la masse énorme de documentation et de références que par la pluridimensionnalité de l'analyse, cette synthèse deviendra rapidement et restera sans doute longtemps une référence incontournable pour les québécistes de toutes disciplines. En effet, y trouvera matière à réflexion quiconque s'intéresse de près ou de loin à la circulation des idées au Québec, à l'évolution des sentiments et des références identitaires, à la naissance puis l'élargissement de la sphère de production culturelle ou aux grandes figures intellectuelles de l'histoire du Québec. Empruntant à la fois à l'histoire des idées et à l'histoire culturelle, dont le foisonnement récent, chez les historiens français, trouve enfin, ici, un répondant de poids, l'Histoire sociale des idées retrace patiemment, en se fondant aussi bien sur des données quantitatives que sur des lectures de textes divers, comment se produit, se répand et se diversifie la culture québécoise, d'époque en époque.

Le premier volume, récemment paru, couvre un peu plus d'un siècle, de la Conquête au début du premier gouvernement de Wilfrid Laurier. En quinze chapitres, très denses, on y retrace la naissance et les transformations de la sphère publique québécoise. De la timide émergence, dans les premières "gazettes" québécoises de la fin du 


\section{RECENSIONS}

XviI ${ }^{e}$ siècle, d'une opinion publique clivée par le conflit entre Britanniques et "Canadiens ", à l'apparition d'une culture des loisirs dans la a fin de siècle culturelle " de 1877-1896; de la culture profondément politisée, marquée par le libéralisme européen et fort intéressée par les mouvements nationalitaires étrangers, propre aux années 1815-1840, à la domination du nationalisme conservateur et de l'ultramontanisme de la seconde moitié du siècle, Yvan Lamonde réécrit l'histoire du Québec en tentant de rendre compte, selon ses propres mots, du * circuit complet des idées, de leur production, de leur diffusion, de leur réception." Si bien des aspects, ici et là, avaient pu être couverts auparavant par quelque étude, jamais encore n'a-t-on eu une histoire des idées embrassant un aussi large horizon avec autant de précision dans le propos et de profondeur dans la documentation.

Mais il ne s'agit pas ici d'une thèse, en ce sens qu'on n'y propose aucun déplacement majeur de perspective ou de révision globale de l'historiographie et que ni polémique larvée ni combat théorique ne guident le projet. On a plutôt droit à une véritable synthèse, à un bilan des recherches sur le sujet. Yvan Lamonde l'indique dans son avantpropos, où il confesse que ses recherches ont été tendues par un "goût de clairière": "De clairière en clairière, me voici debout devant un horizon, avec en mémoire la forêt touffue et ses pistes. Ce récit est l'histoire du chemin parcouru, des marques et des balises mises en place pour que des lecteurs et d'autres explorateurs débouchent aussi sur des horizons. "Cette volonté de parcourir plusieurs chemins explique en partie le plan de l'ouvrage. En effet, en lieu et place d'une narration purement chronologique, L'Histoire sociale des idées poursuit plusieurs pistes parallèles. Chaque période historique sera ainsi vue sous plusieurs angles, ceux de l'histoire des idées proprement dite, de l'histoire des infrastructures culturelles (journaux, librairies, associations, etc.) et de l'histoire des relations intellectuelles. Au cours de ces explorations, plusieurs découvertes attendent le lecteur. On y apprend entre autres quelle importance ont eue les mouvements "nationalitaires "et les révolutions libérales qui ont secoué l'Europe et l'Amérique du Sud de 1808 à 1848, dans les réflexions identitaires des "Canadiens "de l'époque. Tout en fournissant des sources d'inspiration, les exemples étrangers donnèrent aussi matière à réflexion aux Patriotes tentés de les imiter, en 
particulier dans le cas de la Pologne, car "on constate que l'émancipation et l'indépendance d'un pays ne peuvent se faire sans la reconnaissance sinon des métropoles du moins de grandes puissances de l'heure, la Grande-Bretagne, la France et les États-Unis *.

Toutefois, ce qui fait la force des survols historiques de cette ampleur, c'est moins de mettre au jour des faits et des personnages inconnus que de chercher à donner une nouvelle cohérence à des faits et à des trajectoires qui sont déjà connus en bonne partie. Et, dans le cas de l'Histoire sociale des idées au Québec, la trame historique québécoise trouve un autre fil directeur, patiemment poursuivi, celui de l'interaction entre histoire des infrastructures culturelles, d'une part, et histoire des doctrines politiques et des références identitaires, d'autre part. Lamonde fait en effet la démonstration concrète, cas par cas, de l'importance des moyens de production culturelle, des réseaux de diffusion et de la sociabilité dans la constitution des camps idéologiques, la propagation des doctrines, ainsi que pour les représentations collectives. La prémisse n'est sans doute pas neuve, mais la preuve n'en avait pas encore été faite avec autant de force, du moins en ce qui concerne le domaine québécois.

C'est avant tout par cette approche, par la volonté de situer l'émergence et l'évolution des idées dans un contexte de production et de dissémination bien précis que l'histoire des idées proposée dans ce livre se veut une histoire sociale. Car si les positions sociales des protagonistes sont prises en compte jusqu'au chapitre VIII, passé ce cap elles ne prennent plus qu'une place fort restreinte. Quelles étaient les origines sociales des acteurs de la sphère culturelle? Au sein de quels milieux se nouaient les relations entre Québécois et Français? Quelle part prenaient les considérations sociales dans la perception des revendications identitaires étrangères ou québécoises? Quelles couches sociales défendaient le libéralisme radical, le libéralisme modéré ou l'ultramontanisme? On ne trouvera que partiellement, dans cet ouvrage, réponse à ces questions. L'on peut donc dire, à cet égard, que le titre de l'ouvrage suscite des attentes différentes et peut faire naître un reproche partiellement justifié. Avis aux intéressés : vous trouverez dans ce livre une histoire des idées et de leur contexte social de production, 
mais pas une sociologie historique des idées. Ceci dit, on doit ajouter à la défense de la perspective adoptée par Yvan Lamonde que ce dernier ne parle jamais de " surdétermination ", pas plus qu'il n'essaie de plaquer abusivement telle ou telle idéologie sur telle classe ou groupe social particulier. L'on ne trouvera pas trace, par conséquent, dans son livre, du réductionnisme social parfois vengeur qui caractérisait tant de contributions de L'Histoire des idéologies dirigée naguère par Fernand Dumont.

D'autres reproches pourraient certes être formulés, et les spécialistes concernés ne manqueront pas de le faire. L'on jugera sans doute que la part donnée aux libéraux de la seconde moitié du dix-neuvième siècle est fort avantageuse, ce qui donne presque l'impression que ce furent eux, plutôt que les ultramontains, les véritables animateurs de la culture politique canadienne-française de l'époque. L'on pourra penser, de même, que le rôle des communautés religieuses dans la sphère culturelle est légèrement négligé. Et du point de vue des littéraires, parmi lesquels l'auteur de ces lignes doit se ranger, il semblera que la place de la littérature dans la circulation générale des discours est parfois réduite à un statut statistique, où le nombre de textes publiés compre plus que la nature même de ce qui est publié dans ces textes. Néanmoins, il me semble plus important encore d'avancer un souhait, celui de voir une telle histoire sociale des idées servir de base pour une exploration ultérieure de l'histoire des idées au Canada, où seraient étudiés les rapports - et l'absence de rapports - entre les sphères culturelles francophone et anglophone, de même qu'entre les aires géographiques.

Michel Lacroix Institut d'histoire du temps présent (France) 